\title{
TECNOLOGIA DE SEMENTES DE Sebastiania membranifolia Mull Arg (EUPHORBIACEAE)
}

\author{
Neidiquele Maria Silveira1 ${ }^{1}$ José Donizeti Alves², Sara Dousseau ${ }^{3 *}$, Amauri Alves de Alvarenga²
}

*Autora para correspondência: saradousseau@yahoo.com.br

RESUMO: Sebastiania membranifolia, popularmente conhecida como sarandi, é uma espécie arbórea nativa do Brasil, geralmente encontrada em terrenos de várzeas aluviais e beira de rios, indicada para reflorestamentos destinados à recuperação de áreas degradadas. Apesar da importância comercial dessa espécie, pouco se sabe sobre os seus mecanismos de propagação. Nesse contexto, objetivou-se avaliar o comportamento germinativo das sementes em diferentes condições de temperatura, substrato e luz, e determinar métodos de superação de dormência, de forma a estabelecer um protocolo adequado para propagação sexuada. Este estudo foi conduzido em câmaras BOD com controle térmico e de fotoperíodo, testando os seguintes tratamentos: temperaturas de $25 ; 30$ e alternada $20 / 30^{\circ} \mathrm{C}$; substratos (areia-EA; sobre papel-SP e entre papel-EP); quatro soluções de giberelina $\left(50 ; 100 ; 200 ; 400 \mathrm{mgL}^{-1}\right)$; nitrato de potássio $(0,1 ; 0,2 ; 0,3$ e $0,4 \%)$, na presença (12 h de fotoperíodo) e ausência de luz. O delineamento empregado foi em DIC com quatro repetições de 50 sementes cada. Observamos que o grau médio de umidade das sementes foi de $10,4 \%$ e o peso de mil sementes (PMS) de 3,16 g. O maior percentual de germinação foi obtido com fotoperíodo, a $25^{\circ} \mathrm{C}$, sobre papel (SP) e entre papel (EP). As concentrações de $100 \mathrm{mg} \mathrm{L}^{-1}$ de giberelina e $0,1 \%$ de nitrato de potássio proporcionaram maior germinação e vigor. O tratamento das sementes com solução de giberelina a $100 \mathrm{mgL}^{-1}$ favoreceu o crescimento das plântulas, ao contrário do nitrato de potássio que inibiu o crescimento mesmo em baixa concentração.

Palavras-chave: Substrato, luz, temperatura, giberelina, nitrato de potássio.

\section{TECHNOLOGY SEED Sebastiania membranifolia Mull Arg (EUPHORBIACEAE)}

ABSTRACT: Sebastiania membranifolia, popularly known as sarandi, is a tree species native to Brazil, usually found in land of alluvial floodplains and river banks, suitable for restoration of degraded areas. Despite the commercial importance of this species, little is known about its mechanisms of propagation. This research evaluated the germinating seeds under different conditions of temperature, substrate and light, and determined methods of scarification in order to establish a suitable protocol for sexual propagation. The study was conducted in chambers with BOD and thermal control photoperiod, testing the following treatments: temperatures of 25,30 and alternating 20/30 C; substrates (sand-EA, on paper-SP and from paper-EP), four solutions gibberellin (50, 100, 200, $\left.400 \mathrm{mgL}^{-1}\right)$; potassium nitrate (0.1, 0.2, 0.3 and 0.4\%) in the presence (12 $\mathrm{h}$ photoperiod) and absence of light. The experimental design was completely randomized with four replications of 50 seeds each. We found that the average degree of seed moisture was $10.4 \%$ and the weight of a thousand seeds (PMS) of $3.16 \mathrm{~g}$. The highest percentage of germination was obtained with photoperiod at $25^{\circ} \mathrm{C}$, on paper (SP) and between role (EP). The concentrations of $100 \mathrm{mg} \mathrm{L^{-1 }}$ gibberellin and $0.1 \%$ potassium nitrate showed higher germination and vigor. Seed treatment with a gibberellin solution of $100 \mathrm{mgL}^{-1}$ favored the growth of seedlings, unlike potassium nitrate that inhibit the growth even at low concentration.

Key words: Substrate, light, temperature, gibberellin, potassium nitrate.

\section{INTRODUÇÃO}

Sebastiania membranifolia M.Arg(Euphorbiaceae), popularmente conhecida como sarandi, é uma espécie arbórea nativa do Brasil, geralmente encontrada em solos sob alagamento ou sujeito a alagamento. A espécie apresenta importância ecológica e madeireira (LORENZI, 2000), sendo seu emprego voltado, sobretudo para recuperação de áreas degradadas, em especial, para áreas entorno de reservatórios hidrelétricos.

Embora seja uma espécie com potencial comercial e ecológico, são inexistentes estudos referentes à sua propagação sexuada, uma vez que a germinabilidade é baixa e irregular, sugerindo possível dormência. Por essas razões, justificam o desenvolvimento de metodologias eficientes para a formação de mudas, bem como o manejo em larga escala.

A germinação das sementes pode ser definida como a seqüência de eventos fisiológicos que ocorrem antes da protrusão da radícula em sementes embebidas nãodormentes, sendo a etapa que envolve o estabelecimento das plântulas, denominado de evento pós-germinativo (NONOGAKI, 2006). A germinação é mediada por vários fatores ambientais, como umidade, oxigênio, temperatura, luz e nutrientes (SEO et al., 2009; SOCOLOWSKI et al., 2008).

\footnotetext{
${ }^{1}$ Instituto Agronômico de Campinas - Campinas, São Paulo, Brasil

${ }^{2}$ Universidade Federal de Lavras - Lavras, Minas Gerais, Brasil

${ }^{3}$ Instituto Capixaba de Pesquisa, Assistência Técnica e Extensão Rural - Linhares, Espírito Santo, Brasil
} 
Dentre os fatores citados acima, a temperatura e a luz são considerados um dos mais limitantes e decisivos na promoção da germinação (SEO et al., 2009; SOCOLOWSKI et al., 2008). A influência da luz sobre a germinação das sementes é dependente da ação do fitocromo, que altera a sua sensibilidade em função da temperatura (FRANKLIN, 2009; HESCHEL et al., 2007; SIMÃO et al., 2007). Os fitocromos modulam níveis endógenos de giberelina (GA) e ácido abscísico (ABA), bem como a capacidade de resposta de GA (SEO et al., 2009). A germinação e a dormência são processos regulados respectivamente por GA e ABA. A temperatura altera o potencial de crescimento do embrião, bem como influencia nos níveis de ABA e GA (PENFIELD, 2008; TOH et al., 2008; YAMAGUCHI, 2008).

O substrato é um fator complexo que influencia de diversas maneiras no processo germinativo e pósgerminativo. Na escolha do material para substrato, deve ser levado em consideração o tamanho da semente e sua exigência em relação à umidade e luz, considerando principalmente densidade, capacidade de absorção e retenção de água, aeração e drenagem, ausência de pragas, doenças e substâncias tóxicas, além de oferecer facilidade para a avaliação das plântulas (BRASIL, 2009).

Algumas espécies não germinam mesmo quando possuem sementes viáveis e todas as condições ambientais citadas acima, sendo, nesse caso, denominadas dormentes (AZANIA et al., 2009). No caso de dormência endógena, uma das formas de superá-la consiste na aplicação de reguladores de crescimento, como as giberelinas, cofatores ou outras moléculas sinalizadoras, como nitratos (DOMBROSKI et al., 2010; MACEDO et al., 2009; MALAVASI et al., 2011).

Diante do exposto, nosso objetivo foi avaliar os fatores temperatura, substrato e luz, além das diferentes concentrações de giberelina e nitrato de potássio, no processo germinativo das sementes de Sebastiania membranifolia Mull Arg.

\section{MATERIAL E MÉTODOS}

O trabalho foi conduzido no Setor de Fisiologia Vegetal da UFLA, no Laboratório de Crescimento e Desenvolvimento de Plantas. Os frutos foram cedidos pela CEMIG e coletados no período de fevereiro de 2009, no município de Itutinga/MG, situado numa latitude de $21^{\circ} 18^{\prime} 45^{\prime \prime} \mathrm{S}$, longitude de $44^{\circ} 41^{\prime} 15^{\prime \prime} \mathrm{W}$ e altitude de $950 \mathrm{~m}$. A temperatura média anual da região é de $19,4^{\circ} \mathrm{C}$, com uma média das máximas de $28,2^{\circ} \mathrm{C}$ e das míninas de $10^{\circ} \mathrm{C}$ (VILELA; RAMALHO, 1979). O clima da região, segundo Koppen, é do tipo $\mathrm{CWb}$, mesotérmico, com verão chuvoso e inverno seco.

Em condições de laboratório, as sementes foram beneficiadas e armazenadas em sacos plásticos. O grau de umidade foi determinado em base úmida, pelo método da estufa a $105^{\circ} \mathrm{C} \pm 3^{\circ} \mathrm{C}$ por 24 horas (BRASIL, 2009), utilizando-se três repetições de $0,3 \mathrm{~g}$ de sementes. $\mathrm{O}$ peso de mil sementes (PMS) foi determinado segundo Brasil (2009), sendo os resultados expressos em gramas. Foram calculados a variância, o desvio padrão e o coeficiente de variação de $(\mathrm{CV})$, com oito repetições de 100 sementes, do mesmo lote.

No momento da instalação do experimento, as sementes foram desinfestadas com álcool $70 \%$, durante dois minutos, hipoclorito de sódio a $10 \%$ por um minuto e Captan ${ }^{\circledR}$ a $1 \%$ (p/v) por oito minutos.

Para avaliar a interação entre temperatura, substrato e luz na germinação, as sementes foram distribuídas em três substratos distintos: entre areia (EA), sobre papel Germitest ${ }^{\circledR}(\mathrm{SP})$ e entre papel (EP), mantidas nas temperaturas constantes de $25^{\circ} \mathrm{C}, 30^{\circ} \mathrm{C}$ e alternada de 20 $30^{\circ} \mathrm{C}$, na ausência completa de luz e com $12 \mathrm{~h}$ de fotoperíodo, em BOD $60 \% \pm 3$ de umidade relativa. Cerca de $250 \mathrm{~mL}$ de areia foi autoclavada, colocada em gerbox e a semeadura efetuada a aproximadamente $1 \mathrm{~cm}$ de profundidade, para o tratamento EA. Para simulação do escuro, as caixas gerbox e as placas de Petri, foram envoltas em dupla camada de papel alumínio e uma de polietileno preto, sendo a avaliação realizada em sala escura sob luz verde.

A influência de diferentes concentrações de giberelina $\left(\mathrm{GA}_{3}\right)$ e nitrato de potássio $\left(\mathrm{KNO}_{3}\right)$ foram avaliados sobre papel Germtest ${ }^{\circledR}$ saturado com as soluções. As concentrações avaliadas foram 50,100, 200 e $400 \mathrm{mgL}^{-1}$ de $\mathrm{GA}_{3} \mathrm{e} 0,1 \%, 0,2 \%, 0,3 \% \mathrm{e} 0,4 \%$ de $\mathrm{KNO}_{3}$. Como controle, as sementes foram germinadas em substrato saturado com água, na quantidade correspondente a 2,5 vezes o peso do papel. Diariamente foi pulverizada água destilada por meio de um minipulverizador de plástico, mantendo-se o substrato saturado. A germinação foi avaliada diariamente, sendo o critério utilizado a protrusão $\geq$ a $1 \mathrm{~mm}$ de radícula. Para o substrato à areia, foi considerado como critério de germinação, o surgimento do gancho hipocotiledonar. Foram calculados a germinabilidade $(\% \mathrm{G})$, o índice de velocidade de germinação (IVG), segundo Maguire (1962) e a porcentagem de plântulas normais. Também avaliamos o crescimento das plântulas pela influência de diferentes concentrações $\mathrm{GA}_{3}$ e $\mathrm{KNO}_{3}$, observando-se o comprimento do hipocótilo e do sistema radicular.

Cerne, Lavras, v. 19, n. 4, p. 669-675, out./dez. 2013 
O delineamento estatístico empregado foi o inteiramente casualizado, com quatro repetições de 50 sementes por tratamento. $\mathrm{O}$ estudo da interação entre temperatura, substrato e luz na germinação foi conduzido em esquema fatorial, sendo a análise de variância e médias comparadas pelo teste de Tukey, com $5 \%$ de probabilidade. Enquanto que as médias da influência de diferentes concentrações de $\mathrm{GA}_{3}$ e $\mathrm{KNO}_{3}$ foram analisadas por regressão polinomial ou comparadas pelo teste de Tukey, quando a resposta não ajustou as curvas testadas. A análise estatística foi realizada mediante o uso do programa estatístico Sisvar (FERREIRA, 1999).

\section{RESULTADOS E DISCUSSÃO}

O grau de umidade das sementes foi de $10,4 \%$ e o peso de mil sementes (PMS) igual a 3,16 g. Em cada grama de semente contém, aproximadamente 320 sementes.

Quanto à influência da temperatura, substrato e luz na germinação, houve interação tripla para todas as variáveis estudadas, indicando que os três fatores são dependentes.

A luz estimulou a germinabilidade a $25^{\circ} \mathrm{C}$ sobre papel(SP) e $30^{\circ} \mathrm{C}$ entre papel(EP). A característica vigor, foi superior na luz a $25^{\circ} \mathrm{C}$ em EP e SP e a $30^{\circ} \mathrm{C}$ em EA e EP. A $30^{\circ} \mathrm{C}$ e em substrato SP observou-se queda na germinabilidade, provavelmente decorrente do aumento da temperatura, levando ao rápido ressecamento.

De maneira geral, os tratamentos sob condições de luz proporcionaram aumentos significativos para o parâmetro vigor quando comparados aos na ausência de luz, podendo classificá-las como fotoblásticas positivas preferenciais, embora a resposta varie em função da temperatura e substrato. Sabe-se que a luz é um regulador crítico de germinação das sementes (GARCIA et al., 2007; REYES-ORTEGA et al., 2009; SEO et al., 2009). Para outras espécies da família, a resposta é variável, como observado para Croton floribundus cujas sementes são fotoblásticas neutras a $15-30{ }^{\circ} \mathrm{C}$ e a $20-30^{\circ} \mathrm{C}$ (VÁLIO; SCARPA, 2001).

A temperatura altera o potencial de crescimento do embrião, bem como influencia nos níveis hormonais. Em altas temperaturas, pode haver termoinibição pela indução da síntese de ABA (LEYMARIE et al., 2008; TOH et al., 2008) e repressão de GA (TOH et al., 2008), além do que o potencial de crescimento do embrião é reduzido (NONOGAKI, 2006). Por outro lado, em baixas temperaturas, os níveis endógenos de GA são aumentados (PENFIELD, 2008; YAMAGUCHI, 2008). Assim, há uma relação entre requerimento por luz, temperatura e níveis de GA (SEO et al., 2009).
De maneira geral, a maior germinabilidade encontrada foi de aproximadamente $50 \%$ em luz, a $25^{\circ} \mathrm{C}$ em SP e EP e no escuro a $30^{\circ} \mathrm{C} \mathrm{em} \mathrm{SP(Tabela} \mathrm{1).} \mathrm{Resultados}$ divergentes foram obtidos para outras espécies de Euphorbiaceae, em que a maior germinação foi a $20-30^{\circ} \mathrm{C}$ para Sebastiania commersoniana (SANTOS; AGUIAR, 2000), C. floribundus ocorre a $20-30^{\circ} \mathrm{C}$ e é inibida a $25^{\circ} \mathrm{C}$ (ABDO; PAULA, 2006; VÁLIO; SCARPA, 2001) e $J$. curcas, a $20-30{ }^{\circ} \mathrm{C}$ (MARTINS et al., 2008).

Comparando os substratos utilizados, observa-se de modo geral, que a semeadura EP proporcionou melhor capacidade germinativa das sementes e vigor das plântulas.

Com a aplicação de giberelina ( $\left.\mathrm{GA}_{3}\right)$, a concentração de $100 \mathrm{mg} . \mathrm{L}^{-1} \mathrm{de} \mathrm{GA}_{3}$ promoveu a maior germinabilidade, vigor na protrusão radicular e crescimento da plântula normal, comparada as demais (Figura 1).

O papel das giberelinas na germinação está envolvida tanto na indução da germinação, superando a dormência, quanto aumentando o vigor de sementes não dormentes, atuando na síntese de RNA e proteínas específicas da germinação (STENZEL et al., 2003). As GAs são fortes estimuladoras do crescimento tanto da parte aérea como das raízes, sendo o alongamento celular antagonicamente regulado pela luz e por esta classe hormonal, intermediada pelo fitocromo.

Em raízes de Arabidopsis thaliana, o GA representa um importante regulador do crescimento, promovendo tanto o alongamento, quanto a proliferação celular (ACHARD et al., 2009; UBEDA-TOMÁS et al., 2009). Segundo Ubeda-Tomas et al. (2009) o ácido giberélico parece ser necessário para promover e manter o aumento da taxa de crescimento das raízes, por meio do controle do tamanho do meristema por meio da atividade mitótica.

A resposta ao nitrato de potássio $\left(\mathrm{KNO}_{3}\right)$ no processo germinativo pode ser observada na Figura 2. $\mathrm{O}$ maior valor para a germinabilidade (Figura 2 a) e IVG (Figura 2 b) foi obtido a $0,1 \%$, seguido de $0,2 \%$ e $0,3 \%$ que não diferiram do controle. A aplicação de $\mathrm{KNO}_{3}$ influenciou negativamente no desenvolvimento da plântula, sendo observado um decréscimo linear em função do aumento na concentração, tanto para o hipocótilo (Figura $2 \mathrm{c}$ ) quanto para a radícula (Figura $2 \mathrm{~d}$ ).

Especula-se que durante a germinação das sementes, o nitrato absorvido pode atuar como precursor e sinalizador de óxido nítrico durante a germinação das sementes. Segundo Lozano-Juste e León (2010), há interação entre óxido nítrico e ABA no estabelecimento da dormência e germinação, fato confirmado em sementes mutantes de Arabidopsis thaliana.

Cerne, Lavras, v. 19, n. 4, p. 669-675, out./dez. 2013 
Tabela 1 - Percentual de germinação e Índice de velocidade de germinação em sementes de $S$. membranifolia submetidas a diferentes temperaturas, substratos e condição de luz.

Table 1 - Germination percentage and germination rate index in seeds of $S$. membranifolia subjected to different temperatures, substrates and light condition.

\begin{tabular}{|c|c|c|c|c|c|c|}
\hline \multicolumn{7}{|c|}{ Germinabilidade (\%) } \\
\hline \multirow{2}{*}{ Substrato } & \multicolumn{2}{|c|}{$25^{\circ} \mathrm{C}$} & \multicolumn{2}{|c|}{$30^{\circ} \mathrm{C}$} & \multicolumn{2}{|c|}{$20-30^{\circ} \mathrm{C}$} \\
\hline & luz & escuro & luz & escuro & luz & escuro \\
\hline EA & $14,67 \mathrm{bB} a$ & $5,33 \mathrm{cB} a$ & $40,00 \mathrm{aA} a$ & $6,00 \mathrm{cB} a$ & $13,33 \mathrm{bB} a$ & $16,0 \mathrm{bA} a$ \\
\hline $\mathrm{EP}$ & $48,00 \mathrm{aA} a$ & $46,67 \mathrm{aA} a$ & $43,00 \mathrm{aA} a$ & $25,00 \mathrm{bB} b$ & 41,33 aA $a$ & $46,0 \mathrm{aA} a$ \\
\hline SP & $52,00 \mathrm{aA} a$ & $38,00 \mathrm{bB} b$ & $30,67 \mathrm{bCb}$ & $50,00 \mathrm{aA} a$ & $40,00 \mathrm{aB} a$ & $42,67 \mathrm{aB} a$ \\
\hline \multicolumn{7}{|c|}{ Indice de velocidade de germinação (IVG) } \\
\hline \multirow{2}{*}{ Substrato } & \multicolumn{2}{|c|}{$25^{\circ} \mathrm{C}$} & \multicolumn{2}{|c|}{$30^{\circ} \mathrm{C}$} & \multicolumn{2}{|c|}{$20-30^{\circ} \mathrm{C}$} \\
\hline & luz & escuro & luz & escuro & luz & escuro \\
\hline EA & $0,26 \mathrm{bB} a$ & $0,08 \mathrm{bA} a$ & $0,97 \mathrm{abA} a$ & $0,15 \mathrm{cA} b$ & $0,27 \mathrm{bB} a$ & $0,31 \mathrm{bA} a$ \\
\hline EP & $1,37 \mathrm{aA} a$ & $0,96 \mathrm{aB} b$ & $1,22 \mathrm{aA} a$ & $0,54 \mathrm{bCb}$ & $1,29 \mathrm{aA} a$ & $1,25 \mathrm{aA} a$ \\
\hline SP & $1,22 \mathrm{aA} a$ & $0,92 \mathrm{aB} b$ & $0,92 \mathrm{bB} b$ & $1,28 \mathrm{aA} a$ & $1,19 \mathrm{aA} a$ & $1,21 \mathrm{aA} a$ \\
\hline
\end{tabular}

Para cada variável, médias seguidas da mesma letra não diferem entre si pelo teste de Tukey $(\mathrm{p}<0,05)$. Letras minúsculas comparam diferentes substratos dentro de cada condição de luz e temperatura. Letras maiúsculas comparam diferentes temperaturas dentro de cada condição de luz e substrato. Letras minúsculas em itálico comparam diferentes condições de luz dentro de cada substrato e temperatura. For each variable, means followed by the same letter do not differ by Tukey test $(p<0.05)$. Small letters compare different substrates within each light condition and temperature. Capital letters compare different temperatures within each light condition and substrate. Lowercase italic compare different lighting conditions within each substrate and temperature.
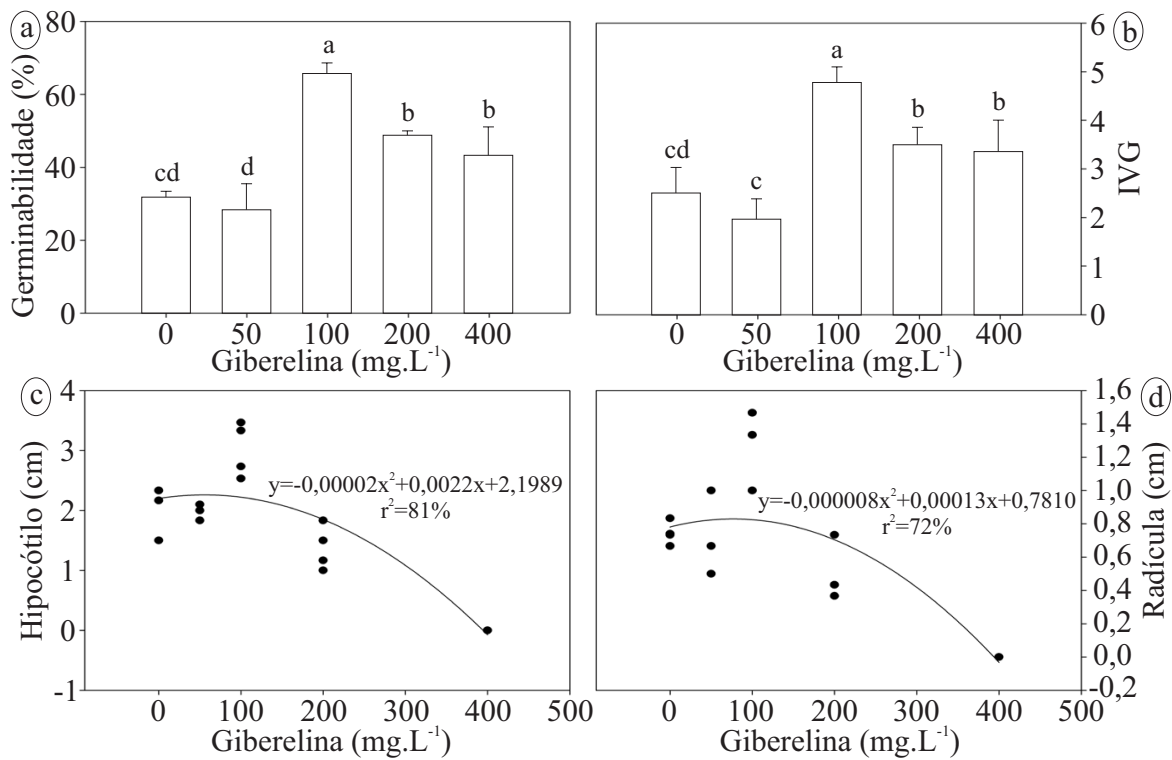

Figura 1 - Comportamento germinativo e pós-germinativo de sementes de $S$. membronifolia submetidas a diferentes concentrações de giberelina $\left(\mathrm{GA}_{3}\right)$. a- Germinabilidade $(\% \mathrm{G})$; b- Índice de velocidade de germinação (IVG); c- Comprimento do hipocótilo; dComprimento da radícula. Para a e b, médias seguidas da mesma letra não diferem entre si pelo teste de Tukey $(\mathrm{p}<0,05)$.

Figure 1 - Behaviour of germination and post-germination of seeds of $S$. membronifolia exposed to different concentrations of gibberellin $\left(G A_{3}\right)$. a- Germinability $(\% G)$ b-index of germination rate (IVG), c-hypocotyl length, $d$-radicle length. For a and b, means followed by the same letter do not differ by Tukey test $(p<0.05)$.

Cerne, Lavras, v. 19, n. 4, p. 669-675, out./dez. 2013 

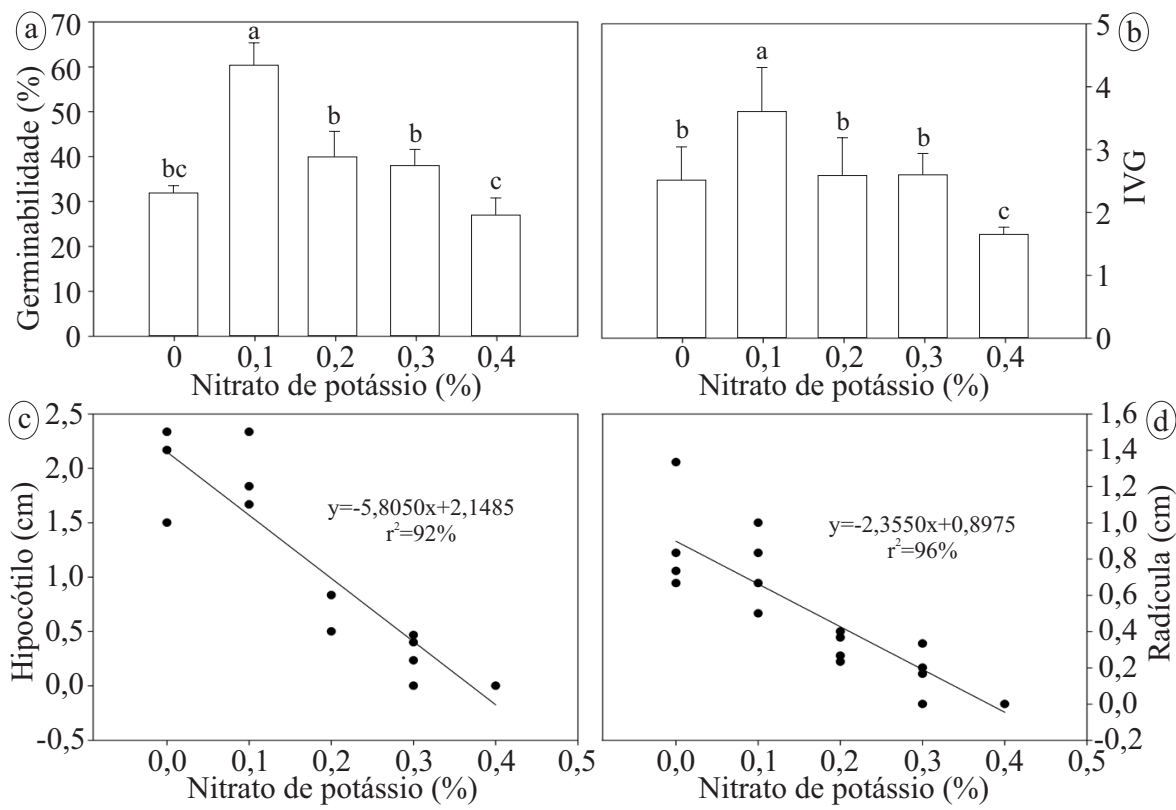

Figura 2 - Comportamento germinativo e pós-germinativo de sementes de $S$. membronifolia submetidas a diferentes concentrações de nitrato de potássio $\left(\mathrm{KNO}_{3}\right)$. a- Germinabilidade $(\% \mathrm{G})$; b- Índice de velocidade de germinação (IVG); c- Comprimento do hipocótilo; d- Comprimento da radícula. Para a e b, médias seguidas da mesma letra não diferem entre si pelo teste de Tukey ( $\mathrm{p}<0,05)$.

Figure 2-Germination and post-germination behavior of seeds of S. membronifolia exposed to different concentrations of potassium nitrate $\left(\mathrm{KNO}_{3}\right)$. a- Germinability $(\% G) b$-index of germination rate (IVG), c-hypocotyl length, $d$-radicle length. For a and $b$, means followed by the same letter do not differ by Tukey test $(p<0.05)$.

\section{CONCLUSÕES}

A germinação das sementes foi implementada pela presença de luz a $25^{\circ} \mathrm{C}$, tendo como substratos sobre papel (SP) e entre papel (EP).

Soluções de ácido giberélico a $100 \mathrm{mgL}^{-1}$ e de nitrato de potássio a $0,1 \%$ foram os tratamento mais eficientes tanto na promoção da germinação como no vigor das plântulas.

Sementes tratadas com solução de giberelina a 100 $\mathrm{mgL}^{-1}$ estimulatam o crescimento de plântulas, ao contrário do nitrato de potássio que inibiu o crescimento mesmo na menor concentração.

\section{AGRADECIMENTOS}

Ao CNPq e FAPEMIG pelo apoio financeiro. A CEMIG por disponibilizar as sementes.

\section{REFERÊNCIAS}

ABDO, M. T. V. N.; PAULA, R. C. Temperaturas para a germinação de sementes de capixingui (Croton floribundus
Spreng - Euphorbiaceae). Revista Brasileira de Sementes, Pelotas, v. 28, n. 3, p. 135-140, 2006.

ACHARD, P.; GUSTI, A.; CHEMINANT, S.; ALIOUA, M.; DHONDT, S.; COPPENS, F.; BEEMSTER, G.

T. S.; GENSCHIK, P. Gibberellin signaling controls cell proliferation rate in Arabidopsis. Current

Biology, Amsterdam, v. 19, p. 1188-1193, 2009.

AZANIA, C. A. M.; MARQUES, R. P.; AZANIA, A. A. P. M.; ROLIM, J. C. Superação da dormência de sementes de corda-de-viola (Ipomoea quamoclit e I. hederifolia). Planta Daninha, Viçosa, v. 27, n. 1, p. 23-27, 2009.

BRASIL. Secretaria de Defesa Agropecuária. Regras para análise de semente. Brasília, 2009. 399 p.

DOMBROSKI, J. L. D.; PAIVA, R.; ALVES, J. M. C.; SANTOS, B. R.; NOGUEIRA, R. C.; PAIVA, P. D. de O.; BARBOSA, S. Métodos para a superação da dormência fisiológica de Caryocar brasiliense Camb. Cerne, Lavras, v. 16, n. 2, p. 131-135, abr./jun. 2010.

Cerne, Lavras, v. 19, n. 4, p. 669-675, out./dez. 2013 
FERREIRA, D. F. SISVAR - Sistema de Análises

Estatísticas. Lavras: UFLA, 1999.

FRANKLIN, K. A. Light and temperature signal crosstalk in plant development. Current Opinion in Plant Biology, Philadelphia, v. 12, p. 63-68, 2009.

GARCIA, Q. de S.; JACOBI, C. M.; RIBEIRO, B. de A. Resposta germinativa de duas espécies de Vellozia (Velloziaceae) dos campos rupestres de Minas Gerais, Brasil. Acta Botanica Brasileira, Feira de Santana, v. 21, n. 2, p. 451-456, 2007.

HESCHEL, M. S.; SELBY, J.; BUTLER, C.; WHITELAM, G. C.; SHARROCK, R. A.; DONOHUE, K. A new role for phytochromes in temperature-dependent germination. New Phytologist, New Jersey, v. 174, p. 735-741, 2007.

LEYMARIE, J.; ROBAYO-ROMERO, M. E.; GENDREAU, E.; BENECH-ARNOLD, R. L.; CORBINEAU, F. Involvement of ABA in induction of secondary dormancy in barley (Hordeum vulgare L.) seeds. Plant and Cell Physiology, Oxford, v. 49, p. 1830-1838, 2008.

LORENZI, H. Árvores brasileiras: manual de identificação e cultivo de plantas arbóreas nativas do Brasil. 2. ed. Nova Odessa: Instituto Plantarum, 2000. v. 2, 115 p.

LOZANO-JUSTE, J.; LEÓN, J. Enhanced abscisic acidmediated responses in nialnia2noa1-2 triple mutant impaired in NIA/NR- and AtNOA1: dependent nitric oxide biosynthesis in arabidopsis. Plant Physiology, Waterbury, v. 152, p. 891903, 2010.

MACEDO, M. C. de; SCALON, S. de P. Q.; SARI, A. P.; SCALON-FILHO, H.; ROSA, Y. B. C. J.; ROBAINA, A. D. Biometria de frutos e sementes e germinação de Magonia pubescens ST.Hil (sapindaceae). Revista Brasileira de Sementes, Londrina, v. 31, n. 2, p. 2022011, 2009.

MAGUIRE, J. D. Speed of germination-aid in selection and evaluation for seedlig emergence and vigor. Crop Science, Madison, v. 2, n. 1, p. 176-177, 1962.

MALAVASI, M. de M.; DIAS, G. B.; MALAVASI, U. C. Effect of gibberellic acid and temperature on germination of

Cerne, Lavras, v. 19, n. 4, p. 669-675, out./dez. 2013
Vitex montevidensis Cham. Cerne, Lavras, v. 17, n. 2, p. 203207, abr./jun. 2011.

MARTINS, C. C.; MACHADO, C. G.; CAVASINI, R. Temperatura e substrato para o teste de germinação de sementes de pinhão-manso. Ciência e Agrotecnologia, Lavras, v. 32, n. 3, p. 863-868, maio/jun. 2008.

NONOGAKI, H. Seed germination-the biochemical and molecular mechanisms. Breeding Science, Oregon, v. 56, p. 93-105, 2006.

PENFIELD, S. Temperature perception and signal transduction in plants. New Phytologist, Davis, v. 179, p. $615-$ $628,2008$.

REYES-ORTEGA, I.; SÁNCHEZ-CORONADO, M. E.; OROZCO-SEGOVIA, A. Seed germination in Marathrum schiedeanum and M. rubrum (Podostemaceae). Aquatic Botany, Amsterdam, v. 90, p. 13-17, 2009.

SANTOS, S. R. G.; AGUIAR, I. B. Germinação de sementes de branquilho (Sebastiania commersoniana (Bill.) Smith \& Downs) em função do substrato e do regime de temperatura. Revista Brasileira de Sementes, Brasília, v. 22, n. 1, p. 120126,2000 .

SEO, M.; NAMBARA, E.; CHOI, G.; YAMAGUCHI, S. Interaction of light and hormone signals in germinating seeds. Plant Molecular Biology, Berlin, v. 69, p. 463-472, 2009.

SIMÃO, E.; SOCOLOWSKI, F.; TAKAKI, M. The epiphytic cactaceae Hylocereus setaceus (Salm-Dick ex DC.) ralf bauer seed germination is controlled by light and temperature.

Brazilian Archives of Biology and Technology, Curitiba, v. 50, p. 655-662, 2007.

SOCOLOWSKI, F.; VIEIRA, D. C. M.; MASSANORI, T. Interaction of temperature and light on seed germination in Tecoma stans L. Juss. ex Kunth (Bignoniaceae). Brazilian Archives of Biology and Technology, Curitiba, v. 51, p. 723730, 2008.

STENZEL, N. M. C.; MURATA, I. M.; NEVES, C. S. V. J. Superação da dormência em sementes de atemóia e fruta-doconde. Revista Brasileira de Fruticultura, Jaboticabal, v. 21, n. 2, p. 305-308, 2003. 
TOH, S.; IMAMURA, A.; WATANABE, A.; NAKABAYASHI, K.; OKAMOT, M.; JIKUMARU, Y.; HANADA, A.; ASO, Y.; ISHIYAMA, K.; TAMURA, N.; IUCHI, S.; KOBAYASHI, M.; YAMAGUCHI, S.; KAMIYA, Y.; NAMBARA, E.; KAWAKAMI, N. High temperature-induced abscisic acid biosynthesis and its role in the inhibition of gibberellin action in Arabidopsis seeds. Plant Physiology, Waterbury, v. 146, p. 1368-1385, 2008.

UBEDA-TOMÁS, S.; FEDERICI, F.; CASIMIRO, I.; BEEMSTER, G. T. S.; BHALERAO, R.; SWARUP, R.; DOERNER, P.; HASELOFF, J.; BENNETT, M. J. Gibberellin signaling in the endodermis controls arabidopsis root meristem size. Current Biology, Amsterdam, v. 19, p. 1194-1199, 2009.
VÁLIO, I. V. F. M.; SCARPA, F. M. Germination of seeds of tropical pioneer species under controlled and natural conditions. Revista Brasileira de Botânica, São Paulo, v. 24, n. 1, p. 79-84, 2001.

VILELA, E. A.; RAMALHO, M. A. P. Análises das temperaturas e precipitações pluviométricas de Lavras, Minas Gerais. Ciência e Prática, Lavras, v. 3, n. 1, p. 71-79, 1979.

YAMAGUCHI, S. Gibberellin metabolism and its regulation. Annual Review of Plant Biology, Palo Alto, v. 59, p. 225251, 2008.

Recebido: 29 de novembro de 2010; aceito: 26 de junho de 2013. 
